Research Article

\title{
Photodegradation of Methyl Green by Nickel-Dimethylglyoxime/ZSM-5 Zeolite as a Heterogeneous Catalyst
}

\author{
Alireza Nezamzadeh-Ejhieh ${ }^{1}$ and Zahra Shams-Ghahfarokhi ${ }^{2}$ \\ ${ }^{1}$ Department of Chemistry, Islamic Azad University, Shahreza Branch, P.O. Box 311-86145, Shahreza, Isfahan, Iran \\ ${ }^{2}$ Young Researcher Club, Islamic Azad University, Shahreza Branch, P.O. Box 311-86145, Shahreza, Isfahan, Iran \\ Correspondence should be addressed to Alireza Nezamzadeh-Ejhieh; arnezamzadeh@iaush.ac.ir
}

Received 12 June 2012; Accepted 10 November 2012

Academic Editor: Huu Hao Ngo

Copyright ( 2013 A. Nezamzadeh-Ejhieh and Z. Shams-Ghahfarokhi. This is an open access article distributed under the Creative Commons Attribution License, which permits unrestricted use, distribution, and reproduction in any medium, provided the original work is properly cited.

\begin{abstract}
Ni-DMG/ZSM-5 zeolite was prepared by ion exchange and complexation procedures. FT-IR, XRD, SEM, TG, and DTG methods were used for characterization of the raw and modified samples. The prepared composite was used as a catalyst in the photodegradation process of an aqueous solution methyl green (MG) dye under UV irradiation. The effect of key operating parameters such as catalyst dosage, temperature, the initial concentration of the dye, and $\mathrm{pH}$ of the samples was studied on the degradation extent of the dye. UV-Vis spectrophotometric measurements were performed for determination of the decolorization and mineralization extents. The optimal operation parameters were found as follows: $\mathrm{pH}=9$, temperature of $60^{\circ} \mathrm{C}, 0.6 \mathrm{~g} \mathrm{~L}{ }^{-1}$ of the catalyst, and $40 \mathrm{ppm}$ of the dye concentration. The Ni-DMG particles out of zeolite framework did not show significant degradation efficiency. The degradation process obeys the first-order kinetic.
\end{abstract}

\section{Introduction}

The amounts of several pollutants present in the surface and underground waters have increased in the last years. Industrial processes generate a variety of molecules that may pollute waters due to negative impacts for ecosystems and humans (toxicity, carcinogenic, and mutagenic properties). Organic dyes are one of the largest group of pollutants released into waste waters from textile and other industrial processes $[1,2]$. Colorants are widely used in different branches of industry, that is, textile, painting, leather, printing, photography, and so forth. Dyes in waste water create aesthetic problems, limit the possible use of the water, and reduce the efficacy of microbial waste water treatment because they may be toxic to microorganisms. Dyes absorb and scatter sunlight which is essential for algae growth [3].

Triphenylmethane dyes are one of the most common organic water pollutants and they are used extensively in the textile industry for dyeing nylon, wool, cotton, and silk, as well as for coloring of oil, fats, waxes, varnish, and plastics.
The paper, leather, cosmetic, and food industries consume a high quantity of triphenylmethane dyes of various kinds. Cationic triphenylmethane dyes have found widespread use as colorants in industry and as antimicrobial agents. Methyl green (MG) is a basic triphenylmethane-type dicationic dye, usually used for staining solutions in medicine and biology and as a photochromophore to sensitize gelatinous films [4]. Cationic (basic) dyes have been used for paper, polyacrylonitrile, modified polyesters, polyethylene terephthalate, and, to some extent, in medicine. Originally they were used for silk, wool, and tannin-mordanted cotton. These water-soluble dyes yield colored cations in solution and that is why they are called cationic dyes [5]. Because of potential toxicity of dyes and their visibility in surface waters, removal and degradation of organic dyes have been a matter of considerable interest [2]. Traditional physical techniques (coagulation, adsorption on activated carbon, reverse osmosis, etc.) can generally be used for removal of such pollutants. Nevertheless, these methods are usually nondestructive, and the posttreatment 
of the adsorbent materials or solid wastes is necessary and expensive [6].

A relatively newer, more powerful and very promising approach called advanced oxidation processes (AOPs) has been developed and employed to treat dye-contaminated waste water effluents [7]. AOPs are a set of techniques which normally utilize a strong oxidizing species such as ${ }^{\bullet} \mathrm{OH}$ radicals produced in situ which causes a sequence of reactions thereafter to break down the macromolecule into smaller and less harmful substances. In many cases, the macromolecule is completely broken down to water and carbon dioxide [8]. AOPs include also many techniques, such as methods based on ultrasound [9], plasma [10], and electrohydraulic discharge [11] along with processes based on hydrogen peroxide $\left(\mathrm{H}_{2} \mathrm{O}_{2}+\mathrm{UV}\right.$, Fenton, photo-Fenton, and Fenton-like processes), photolysis, processes based on ozone $\left(\mathrm{O}_{3}, \mathrm{O}_{3}+\right.$ $\mathrm{UV}$ and $\mathrm{O}_{3}+$ catalyst) [12], photocatalysis by semiconductors $\left(\mathrm{TiO}_{2} / \mathrm{UV}\right)[13,14]$, and photoredox reactions of transition metal complexes [15]. Some of the oxides like $\mathrm{TiO}_{2}$ showed outstanding activities [16, 17]. However, the liw surface area, limited thermal stability, and unsuitable mechanical properties prevented their commercial exploitation [18]. In this paper, degradation of methyl green using photoredox reactions of transition metal complexes is investigated.

Transition metal complexes play a special role in the environmental processes. Their easiness in change of the oxidation state makes the transition metal ions responsible for most redox processes occurring in nature directly or via a catalytic mechanism. Due to presence of unpaired electrons the metal ions react readily with molecular oxygen, mediating thereby oxygenation of other compounds, especially those constituting the natural organic matter [15].

Nickel(II) dimethylglyoxime complex (Ni-DMG) is considered on attractive approach for the degradation of methyl green (MG). To increase the activity of semiconductors in photodegradation experiments, suitable supports have been used to improve the efficiency of the photocatalytic process. Among the supports, zeolites have more advantageous owing to their special features such as high surface area, hydrophobic and hydrophilic properties, tunable chemical properties, high thermal stability, and eco-friendly nature [19]. Yan et al. inferred that Al-O units in framework of the zeolite were the photocatalytic active sites [20]. Zeolites modified with transition metal cations have received increasing attention as promising catalysts for a variety of important reactions [21]. Zeolites can serve as hosts to activate transition metal cations, offering a unique ligand system with multiple types of coordination for cations. In addition, the restricted pore size of zeolites could limit the growth or sintering of the nanoparticles of the cation even at high temperatures [22]. ZSM-5 zeolite, with highly ordered micropores, surface acidity, and ion-exchange properties, is one of the most widely applied inorganic materials as catalysts support, adsorbents, and molecular-sized spaces for various chemical or photochemical reactions [23].

In the present study, ZSM-5 zeolite was synthesized and characterized with FT-IR, XRD, SEM, TG, and DTG methods. ZSM-5 zeolite was exchanged with $\mathrm{Ni}(\mathrm{II})$ solution and then nickel (II) dimethylglyoxime/ZSM-5 photocatalyst was

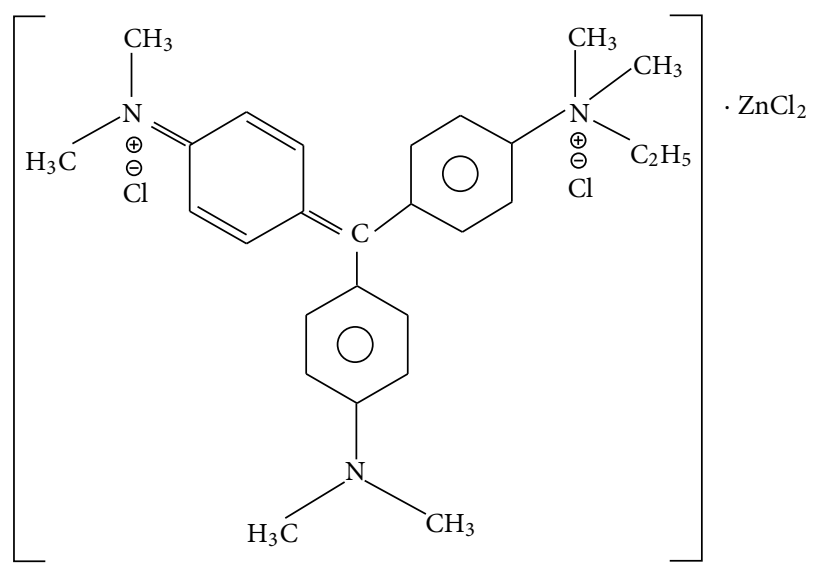

FIGURE 1: Chemical structure of MG.

prepared. The activity of the Ni-DMG/ZSM-5 photocatalyst was evaluated by studying the photocatalytic decolorization of methyl green. The effect of catalyst dosage, methyl green concentration, $\mathrm{pH}$, and temperature was studied on the photodecolorization extent under UV irradiation and corresponding dark controls were also carried out for comparison. Finally, the relative photonic efficiency of Ni-DMG supported catalyst and pure Ni-DMG was compared.

\section{Experimental}

2.1. Materials. $\mathrm{MG}$ dye (molecular formula: $\mathrm{C}_{27} \mathrm{H}_{35} \mathrm{Cl}_{2} \mathrm{~N}_{3}$ ), dimethylglyoxime (DMG, $\mathrm{C}_{4} \mathrm{H}_{8} \mathrm{~N}_{2} \mathrm{O}_{2}$ ), sodium silicate (composition: $\mathrm{SiO}_{2} ;(25.2 \%-28.5 \%), \mathrm{Na}_{2} \mathrm{O}$ (7.5\%-8.5\%), $\mathrm{H}_{2} \mathrm{O}(63 \%)$ ), nickel nitrate hexahydrate, hydrochloric acid (37\%), tetrapropylammonium bromide (TPABr 98\%), aluminum sulfate eighteen hydrate $(>99.3 \%)$, and other used chemicals were supplied from Merck. The chemical structure of the MG dye is displayed in Figure 1 [4]. Deionized water was used throughout the experiments.

2.2. Synthesis of ZSM-5 Zeolite. $2.4984 \mathrm{~g}(42.7 \mathrm{mmol})$ sodium chloride and $0.5931 \mathrm{~g}(0.89 \mathrm{mmol})$ hydrated aluminum sulfate were dissolved in $10.1200 \mathrm{~g}(562.2 \mathrm{mmol})$ distilled water. $1.8945 \mathrm{~g}(7.12 \mathrm{mmol})$ tetrapropylammonium bromide, $7.1200 \mathrm{~g}$ ( $395.5 \mathrm{mmol})$ distilled water, and $1.0883 \mathrm{~g}$ $(10.88 \mathrm{mmol})$ sulfuric acid were added with vigorous stirring. $15.0000 \mathrm{~g}\left(71.25 \mathrm{mmol} \mathrm{SiO}_{2}\right)$ sodium silicate solution was subsequently added and the mixture was stirred for $60 \mathrm{~min}$. The $\mathrm{pH}$ of the mixture was 9.4. The mixture was transferred into the autoclave. The autoclave was kept into an oven at $110^{\circ} \mathrm{C}$ for about $2 \mathrm{~h}$. Then, the temperature was increased to $230^{\circ} \mathrm{C}$ and kept at that level for another $5 \mathrm{~h}$. The solid phase obtained was filtered out, washed with water several times, dried at $110^{\circ} \mathrm{C}$ for about $12-14 \mathrm{~h}$, and subsequently calcined at $540^{\circ} \mathrm{C}$ for $3 \mathrm{~h}$ [24].

2.3. Preparation of Catalysts. Ni-ZSM-5 sample was prepared using the conventional ion exchange procedure [25]. $1 \mathrm{~g}$ Na-ZSM- 5 was added to $50 \mathrm{~mL}$ of $0.1 \mathrm{M} \mathrm{Ni}\left(\mathrm{NO}_{3}\right)_{2} \cdot 6 \mathrm{H}_{2} \mathrm{O}$ 
solution with constant stirring at room temperature. After $12 \mathrm{~h}$, the particles were filtered off and washed with deionized water till complete removal of $\mathrm{Ni}^{2+}$ ions. The obtained sample was first dried at $120^{\circ} \mathrm{C}$ for $12 \mathrm{~h}$ and calcined at $500^{\circ} \mathrm{C}$ for $6 \mathrm{~h}$. The obtained material has a light green color.

About $1 \mathrm{~g}$ of dried nickel exchanged zeolite was slowly added into the $25 \mathrm{~mL}$ DMG ( $1 \%$ in ethanol) and stirred for $24 \mathrm{~h}$. The resulting bright red color material was filtered, washed with excess water, and dried at room temperature. The obtained sample was Ni-DMG/ZSM-5. In a typical preparation of Ni-DMG, $1 \mathrm{~g} \mathrm{Ni}\left(\mathrm{NO}_{3}\right)_{2} \cdot 6 \mathrm{H} 2 \mathrm{O}$ was added to a $25 \mathrm{~mL}$ of DMG solution, followed by stirring for $30 \mathrm{~min}$. The mixed solution was centrifuged, and the precipitate was washed for several times with distilled water and dried at room temperature. Finally, the red Ni-DMG powder was obtained.

2.4. Catalyst Characterization. Fourier transform infrared (FT-IR) spectra of all samples were taken in $\mathrm{KBr}$ pellets in the $4000-400 \mathrm{~cm}^{-1}$ region using Nicolet 400D-Impact FT-IR spectrophotometer. Powder X-ray diffraction (XRD) pattern for the ZSM-5 zeolite was carried out using Bruker D8ADVANCE equipment with an X-ray source of $\mathrm{CuK} \alpha$ radiation. Thermograms were performed for the samples $(6 \mathrm{mg})$ using model Setaram STA units in the range of $50-800^{\circ} \mathrm{C}$ with temperature rise of $10^{\circ} \mathrm{C} \mathrm{min}^{-1}$. The morphology and crystal size of the samples were visualized by scanning electron microscopy (CAM SCAN 44, Cambridge). The amount of Ni present in the Ni-ZSM-5 and Ni-DMG/ZSM5 was measured by Atomic absorption spectrometry (AAS) using an atomic absorption spectrometer (Perkin-Elmer 300 Analyst). The MG content of solutions was analyzed using UV-Vis spectrophotometer (Cary 100, Varian, Australia).

2.5. Photocatalytic Decolorization Procedure. Photocatalytic decolorization of MG was performed in $40 \mathrm{~mL}$ aqueous solution containing $20 \mathrm{ppm}$ MG. A constant weight of $0.6 \mathrm{~g} \mathrm{~L}^{-1}$ of Ni-DMG/ZSM- 5 was added into the solution. The benchscale system is a cylindrical Pyrex-glass cell with $5 \mathrm{~cm}$ inside diameter and $10 \mathrm{~cm}$ height. Irradiation experiments were performed using medium pressure Hg lamp ( $55 \mathrm{~W}, 332 \mathrm{~nm}$ ), then it was placed in a $5 \mathrm{~cm}$ diameter quartz tube with one end tightly sealed by a Teflon stopper. The lamp and the tube were then immersed in the photoreactor cell with a light path of $30 \mathrm{~cm}$. A magnetic stirrer was continuously working at the bottom of the reaction solution. The experiment was performed at room temperature. After irradiation, the sample was centrifuged to remove the solid catalyst. The MG content was analyzed quantitatively by measuring the absorption band at $632 \mathrm{~nm}$ using UV-Vis spectrophotometer. This experiment was carried out by Ni-DMG compound too. The elimination of MG due to adsorption was measured by carrying out similar experiments in dark. The decolorization of MG by Ni-DMG/ZSM- 5 catalyst was studied under different initial dye concentrations (10-100 ppm), initial solution pHs (1.0-9.0), solution temperature $\left(25-60^{\circ} \mathrm{C}\right)$, and catalyst dosage $\left(0.2-1.0 \mathrm{~g} \mathrm{~L}^{-1}\right)$ to optimize the reaction conditions. Each experiment was conducted in duplicate.
The reaction order with respect to $\mathrm{Mg}$ was determined by plotting reaction time versus $\log [\mathrm{MG}]$ according to the following equation:

$$
\log [C]_{t}=-k t+\log [C]_{0},
$$

where $[C]_{0}$ and $[C]_{t}$ represent the concentration of the substrate in solution at zero time and t time of irradiation, respectively, and $k$ represents the apparent rate constant $\left(\mathrm{min}^{-1}\right)[16]$.

\section{Results and Discussion}

\subsection{Catalyst Characterization}

3.1.1. X-Ray Diffraction Studies. The X-ray diffraction patterns of ZSM-5 zeolite, Ni-ZSM-5, and Ni-DMG/ZSM-5 are shown in Figure 2. The characteristic lines where located at $2 \theta$ degree of $8,9,23$, and 24 (Figure 2(a)) have good agreement with the data of reference Na-ZSM-5 [26]. The presence of the weak peaks in $2 \theta$ value of $10^{\circ}$ and $27.4^{\circ}$ in the Ni-ZSM-5 and Ni-DMG/ZSM-5 patterns (Figure 2(b), (c)), that are not present in the pattern of ZSM-5 (Figure 2(a)), indicate the incorporation of $\mathrm{Ni}^{2+}$ in the zeolite structure. The powder XRD results of ZSM-5 and the host-guest composite materials (Ni-ZSM-5 and Ni-DMG/ZSM-5) show similar diffraction peaks indicative of ZSM-5. But some differences such as increasing or decreasing of some peaks intensity can be observed in the spectra [27]. In fact it can be related to the presence or incorporation of $\mathrm{Ni}^{2+}$ in the matrix structure. Using Sherrer equation [28], crystal sizes of the ZSM-5, NiZSM-5, and Ni-DMG/ZSM-5 were measured by XRD as: 3.6, 3.5 and $3.4 \mu \mathrm{m}$, respectively.

3.1.2. FT-IR Studies. FT-IR lattice vibration spectra were used to investigate the influence of nickel and Ni-DMG on the zeolite framework. The FT-IR transmission spectra for ZSM-5 zeolite, Ni-ZSM-5, Ni-DMG/ZSM-5, and NiDMG are shown in Figure 3. From Figure 3(a), the infrared absorption peaks of ZSM-5 appeared at 446, 547, 786, 1077, $1230,1483,1637$, and $3319 \mathrm{~cm}^{-1}$. The presence of the infrared band at $547 \mathrm{~cm}^{-1}$ has been assigned to the five-membered ring of the pentasil zeolite structure. Additional evidence for ZSM-5 is the asymmetric stretch vibration of the T-O band at $1230 \mathrm{~cm}^{-1}$ (where $\mathrm{T}$ is $\mathrm{Si}$ or $\mathrm{Al}$ ), which has been assigned to external linkages (between $\mathrm{TO}_{4}$ tetrahedral) and is a structure-sensitive IR band of ZSM-5 [26, 29, 30].

Infrared spectroscopy can reflect the change of the framework configuration of the zeolite host after the incorporation of the guests. In Figure 3(b), the FT-IR spectrum of NiZSM-5 shows a distortion of the spectrum between 1250 and $900 \mathrm{~cm}^{-1}$. This region of the spectrum was assigned to asymmetrical $\mathrm{T}-\mathrm{O}-\mathrm{T}$ stretching and is indicative of heteroatom substitution [31]. Changes of the characteristic peaks took place between the host zeolite ZSM-5 (the values in the parentheses) and the host-guest materials Ni-ZSM5 and Ni-DMG/ZSM-5. For Ni-ZSM-5, the characteristic bands are seen at $456(446) \mathrm{cm}^{-1}, 556(547) \mathrm{cm}^{-1}$ (T-O bend), 


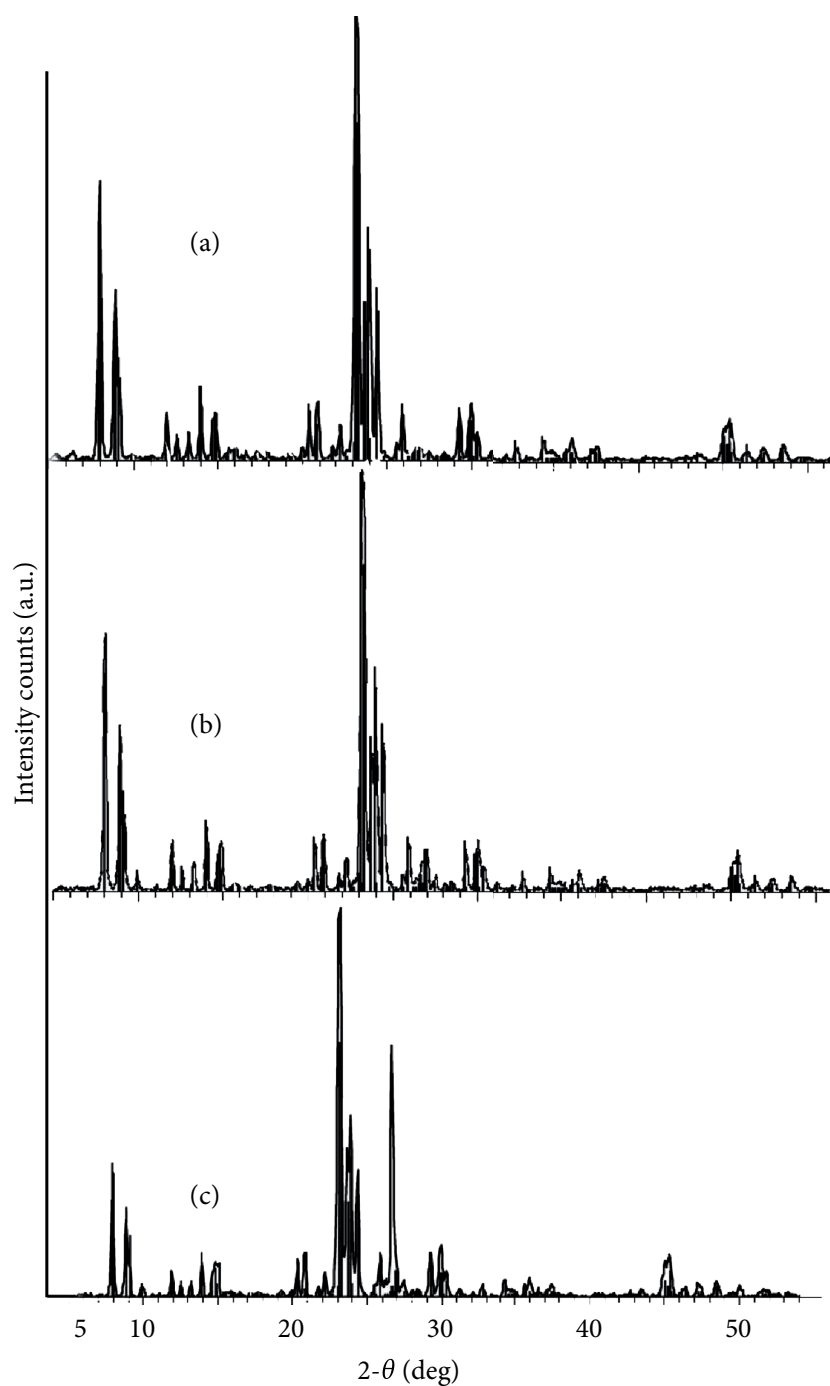

FIGURE 2: XRD patterns of Na-ZSM-5 (a), Ni-ZSM-5 (b), and NiDMG/ZSM-5 (c).

791 (786) $\mathrm{cm}^{-1}$ (symmetrical stretch), $1080(1082) \mathrm{cm}^{-1}$ (asymmetrical stretch), and $1235(1260) \mathrm{cm}^{-1}$ that show a shift of some bands as compared with the bands of ZSM-5 host (Figures 3(a) and 3(b)). These results confirm the incorporation of $\mathrm{Ni}^{2+}$ cations into zeolite channels. Furthermore, the presence of the peaks at 2410 and $2960 \mathrm{~cm}^{-1}$ in the NiZSM-5 and Ni-DMG/ZSM-5 spectra, which are not present in the spectrum of ZSM-5, indicates the incorporation of $\mathrm{Ni}^{2+}$ into zeolite. In addition, the greenish blue color after ion exchange with $\mathrm{Ni}^{2+}$ cations can be considered as a primary evidence for incorporation of $\mathrm{Ni}^{2+}$ into zeolite framework.

Similar results will be shown for Ni-DMG/ZSM-5 at 467, $568,805,1090$, and $1290 \mathrm{~cm}^{-1}$ (Figure 3(c)). Comparison of the spectra of (b) and (c) in Figure 3 show the changes due to conversion of $\mathrm{Ni}^{2+}$ ions that is present in zeolite to $\mathrm{Ni}$ DMG. These results demonstrated that the guest Ni-DMG incorporated into the ZSM-5 zeolite had some interactions with the inner surfaces of zeolite host at the same time. The

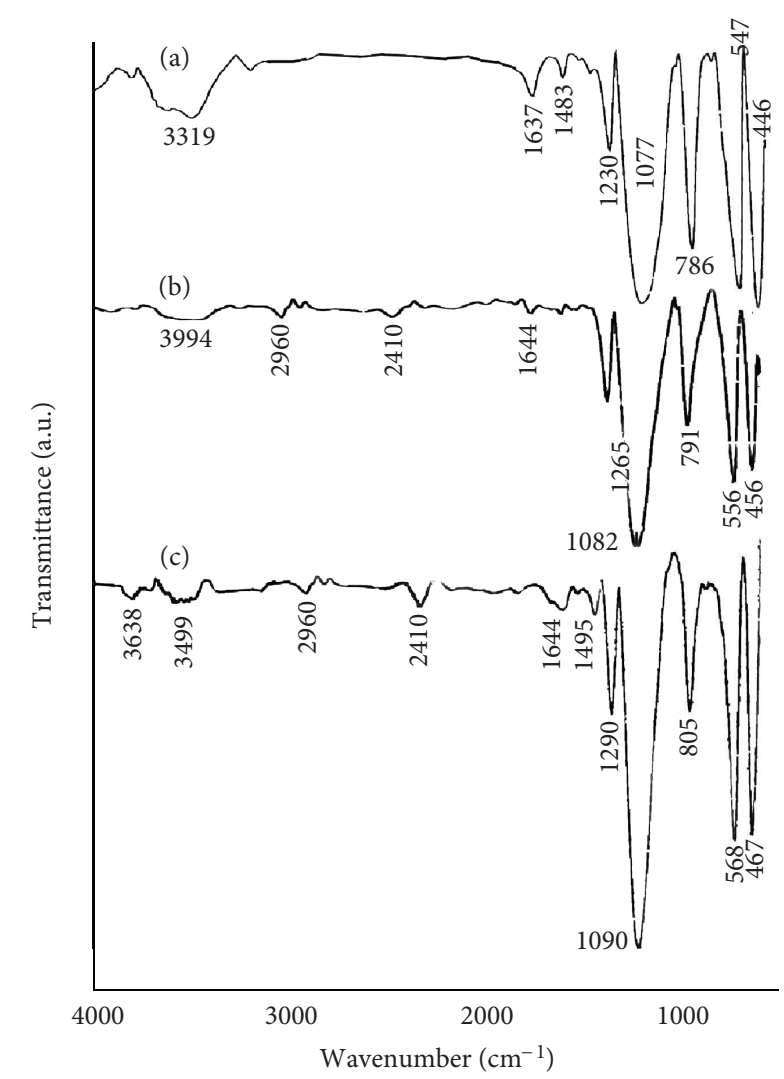

FIgURE 3: FTIR spectra of Na-ZSM-5 (a), Ni-ZSM-5 (b), and NiDMG/ZSM-5 (c).

greenish blue color of the Ni-ZSM-5 changes to bright red after precipitation with DMG which confirms conversion of $\mathrm{Ni}^{2+}$ to Ni-DMG in the zeolite.

Generally, acidity of the framework increases with increasing the $\mathrm{M}^{2+}$ substitution, but there was no obvious trend in the absorption bands assigned to terminal hydroxyl groups $\left(3734 \mathrm{~cm}^{-1}\right)$, or to the absorption bands assigned to bridging hydroxyl groups associated with a Bronsted site $\left(3650-3600 \mathrm{~cm}^{-1}\right)$ [32].

3.1.3. Thermal Analysis. The TG and DTG curves of ZSM5, Ni-ZSM-5, and Ni-DMG/ZSM-5 are shown in Figure 4. The TG results for ZSM-5 zeolite are similar to the literature [33]. The peak at $200^{\circ} \mathrm{C}$ (Figure 4(c)) may be related to lose of excess of DMG that remained due to incomplete washing of the zeolite after complexation process. The increase in weight below $350^{\circ} \mathrm{C}$ is a result of oxygen adsorption.

3.1.4. SEM Analysis. The surface morphology of ZSM-5 zeolite ((a), (b)) Ni-ZSM-5 ((c), (d)) and Ni-DMG/ZSM-5 ((e), (f)) was studied by scanning electron microscope and the SEM pictures are presented in Figure 5. The images of loaded samples (Ni-ZSM-5 and Ni-DMG/ZSM-5) show that crystallinity is not affected by the $\mathrm{Ni}^{2+}$ loading. But it seems that particles break to pieces with loading $\mathrm{Ni}^{2+}$ in the 


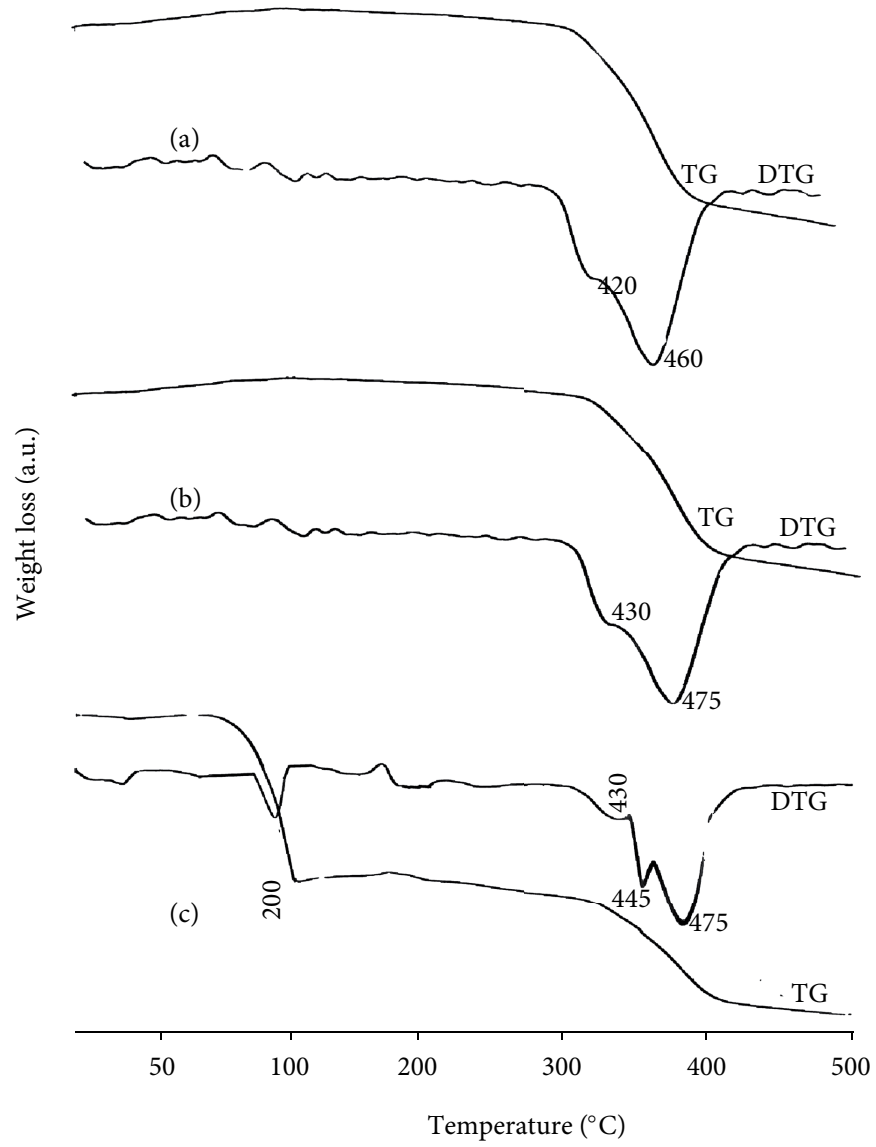

Figure 4: Thermal analysis curves spectra of Na-ZSM-5 (a), Ni-ZSM-5 (b), and Ni-DMG/ZSM-5 (c).

zeolite. Increasing activity of loaded samples may be related to dwindling in size of particles.

\subsection{Photocatalytic Decolorization of $M G$ by Ni-DMG/ZSM-5}

3.2.1. Effect of Catalyst Concentration. The initial rate of the photocatalytic degradation of many pollutants is a function of the photocatalyst dosage $[15,34]$. A series of experiments was carried out to assess the optimum catalyst loading by varying the amount of the catalyst from 0.2 to $1.0 \mathrm{~g} \mathrm{~L}^{-1}$ with MG concentration (20 ppm). The results depicted in Figure 6 show that the degradation rate increases with increasing the mass of the catalyst, reached the highest value $\left(0.6 \mathrm{~g} \mathrm{~L}^{-1}\right.$ of the catalyst) and then decreased considerably. The reason for this decrease is thought to be the fact that when the concentration of the catalyst rises, the solid particles increasingly block the penetration of the photons. So the overall number of the photons that can be reached to catalyst particles and hence the production of $\mathrm{OH}$ radicals decrease [35]. Another reason may be due to the aggregation of solid particles while using a large amount of catalyst $[4,36]$. Also, Figure 6 shows that the removal rates were negligible in the absence of catalyst or dark condition after $3 \mathrm{~h}$ control.

Many authors have reported that the kinetic behavior of the photocatalytic reactions obeys the first-order reaction
$[35,36]$. In order to confirm the speculation, $\ln \left(C / C_{0}\right)$ was plotted as a function of the irradiation time. The calculated results indicated that the first-order model gives a better fit. The rate constant values, $k\left(\mathrm{~min}^{-1}\right)$, are calculated from the straight-line segment of the first-order plots as a function of the catalyst mass and are listed in Table 1. As the results show, maximum degradation (76.5\%) of MG. dye was observed after $120 \mathrm{~min}$ with the maximum rate constant $(3.6$ $\times 10^{-2} \mathrm{~min}^{-1}$ ) in the presence of $0.6 \mathrm{~g} \mathrm{~L}^{-1}$ of the catalyst. Methyl green alone could not be transformed under UV irradiation, corresponding to the rate constant $(k)$ of $3.0 \times$ $10^{-5} \mathrm{~min}^{-1}$. In the following experiments, we chose $0.6 \mathrm{~g} \mathrm{~L}^{-1}$ of Ni-DMG/ZSM-5 as the optimum dosage.

3.2.2. Effect of $p H$. The waste water from the textile industries usually has a wide range of $\mathrm{pH}$ values. Generally $\mathrm{pH}$ plays an important role both in the characteristics of textile wastes and generation of active sites [37]. Hence, the role of $\mathrm{pH}$ on the degradation extent of $\mathrm{MG}$ was studied in the $\mathrm{pH}$ range of 1-9 in $20 \mathrm{ppm}$ MG concentration containing $0.6 \mathrm{~g} \mathrm{~L}^{-1}$ of the catalyst. At pHs above 9, the solution was colorless and the $\lambda_{\text {max }}$ of the MG was shifted to UV region (before $250 \mathrm{~nm}$ ) and hence a decrease in the absorbance of the solution during the degradation process was not distinguishable. Hence, the corresponding results was not measured. The solution of $\mathrm{pH}$ 


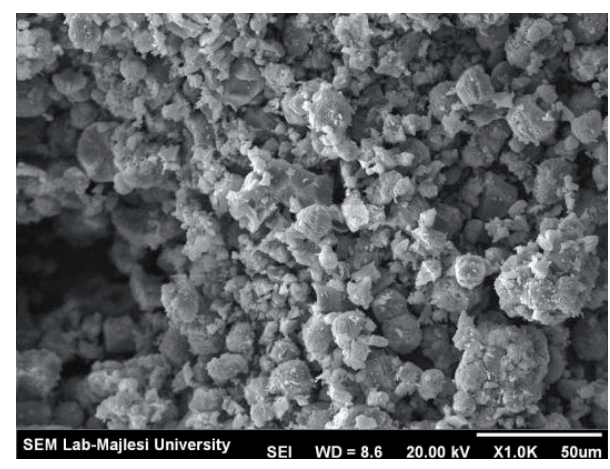

(a)

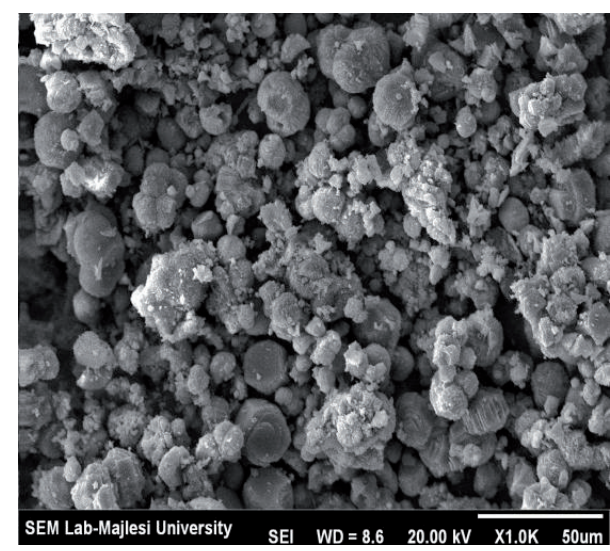

(c)

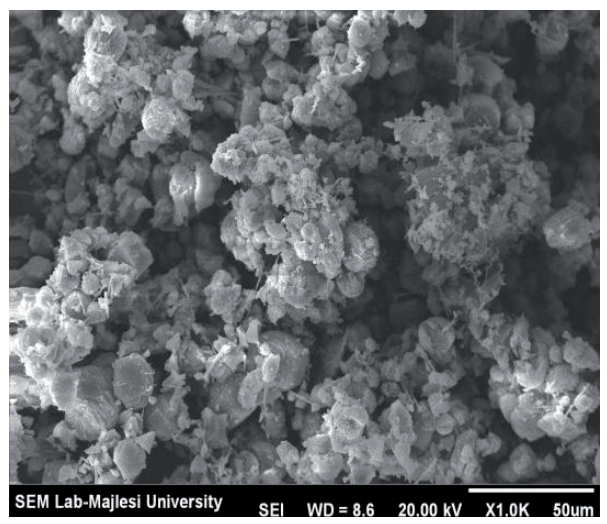

(e)

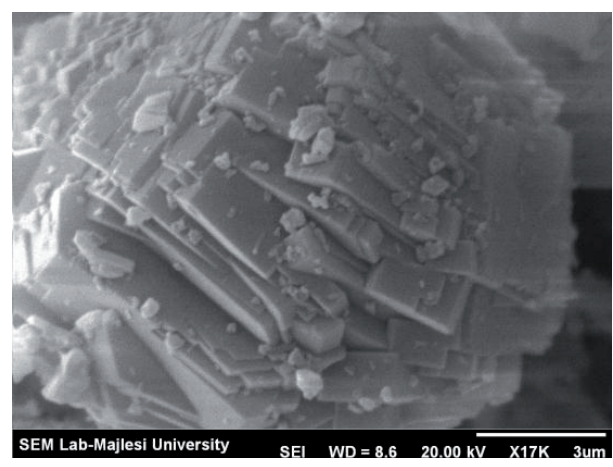

(b)

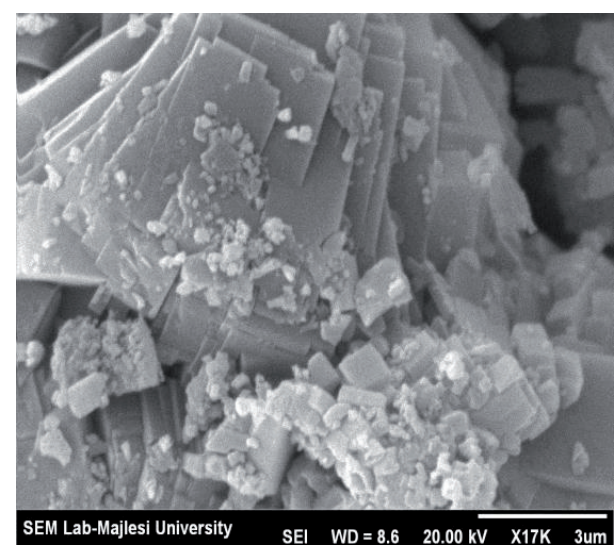

(d)

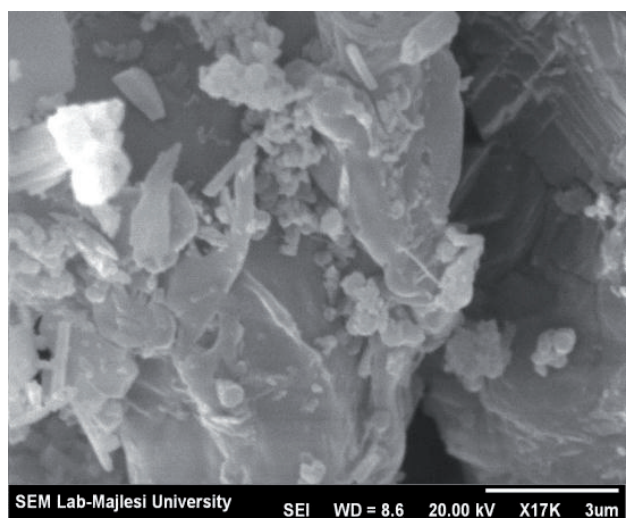

(f)

Figure 5: SEM images of Na-ZSM-5 ((a), (b)); Ni-ZSM-5 ((c), (d)) and Ni-DMG/ZSM-5 ((e), (f)).

was adjusted only prior to irradiation and was not controled during the reaction. As shown in Figure 7, the percentage of decolorization increased with increasing $\mathrm{pH}$. As mentioned in the literature [35], in the initial acidic pHs, concomitant with acidification of the solution by $\mathrm{HCl}$, a high amount of conjugated base is added to the solution. The anion $\mathrm{Cl}^{-}$ is able to react with hydroxyl radicals leading to inorganic radical ions $\left(\mathrm{ClO}^{-\bullet}\right)$. These inorganic radical anions show a much lower reactivity than ${ }^{\circ} \mathrm{OH}$, so that they do not take part in the dye decolorization. There is also a drastic competition between the dye and anions with respect to ${ }^{\bullet} \mathrm{OH}$. Hence, increasing $\mathrm{pH}$ shows an increase in the degradation efficiency. Alkaline pHs favor the formation of more $\mathrm{OH}$ radicals due to the presence of large quantity of $\mathrm{OH}^{-}$anions in the alkaline medium, which enhances the photocatalytic degradation of MG significantly [25]. In acidic solutions a decrease in the decolorization rate was observed reflecting the difficulty of the dye molecules to approach the catalyst surface due to electrostatic interactions. In other words, at low $\mathrm{pH}$, the adsorption of cationic dye on the surface of 


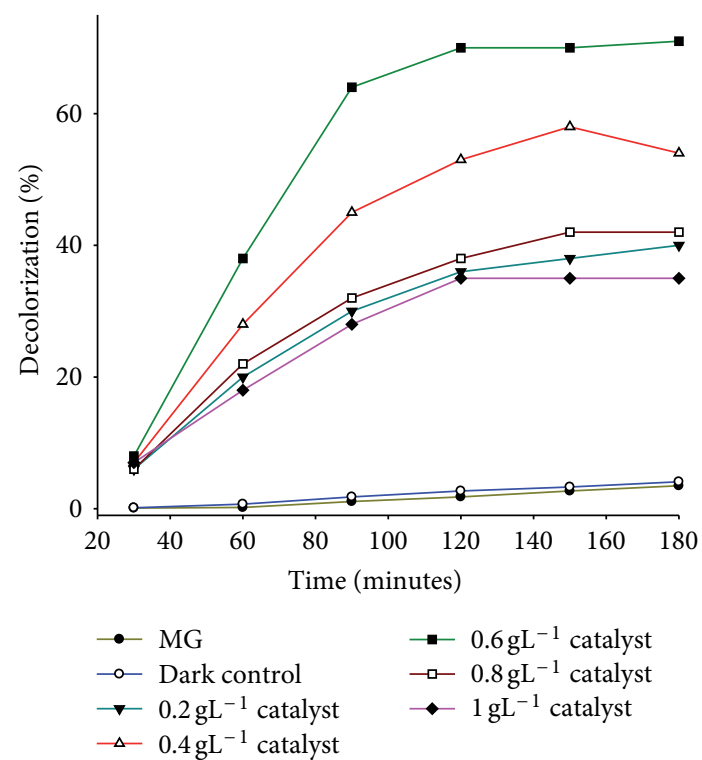

FIGURE 6: Effect of Ni-DMG/ZSM-5 dosage on the decolorization efficiency of MG dye; initial dye concentration, $20 \mathrm{ppm}$; initial $\mathrm{pH}$, 5.3; photocatalyst dosage, $\left(0.2,0.4,0.6\right.$ and $\left.0.8 \mathrm{~g} \mathrm{~L}^{-1}\right)$; $55 \mathrm{~W} \mathrm{Hg}$ lamp; continuous stirring; irradiation time, $180 \mathrm{~min}$; room temperature.

TABLE 1: Rate constant values as a function of various experimental parameters.

\begin{tabular}{|c|c|c|}
\hline Parameter & Value & $k \times 100\left(\min ^{-1}\right)$ \\
\hline \multirow{6}{*}{ Catalyst amount $\left(\mathrm{g} \mathrm{L}^{-1}\right)$} & 0 & 0.003 \\
\hline & 0.2 & 0.9 \\
\hline & 0.4 & 1.9 \\
\hline & 0.6 & 3.6 \\
\hline & 0.8 & 1.7 \\
\hline & 1.0 & 0.46 \\
\hline \multirow{5}{*}{$\mathrm{pH}$} & 1 & 0 \\
\hline & 3 & 1.1 \\
\hline & 5 & 4.6 \\
\hline & 7 & 5.2 \\
\hline & 9 & 6.1 \\
\hline \multirow{5}{*}{ Temperature $\left({ }^{\circ} \mathrm{C}\right)$} & 25 & 1.8 \\
\hline & 40 & 2.4 \\
\hline & 50 & 2.7 \\
\hline & 60 & 3.5 \\
\hline & 80 & 4.3 \\
\hline \multirow{6}{*}{$C_{\mathrm{MG}}(\mathrm{ppm})$} & 10 & 0.10 \\
\hline & 20 & 0.46 \\
\hline & 40 & 2.11 \\
\hline & 60 & 0.6 \\
\hline & 80 & 0.44 \\
\hline & 100 & 0.29 \\
\hline
\end{tabular}

the photocatalyst was decreased because the photocatalyst surface will be positively charged and repulsive force is due to decreasing adsorption [34].

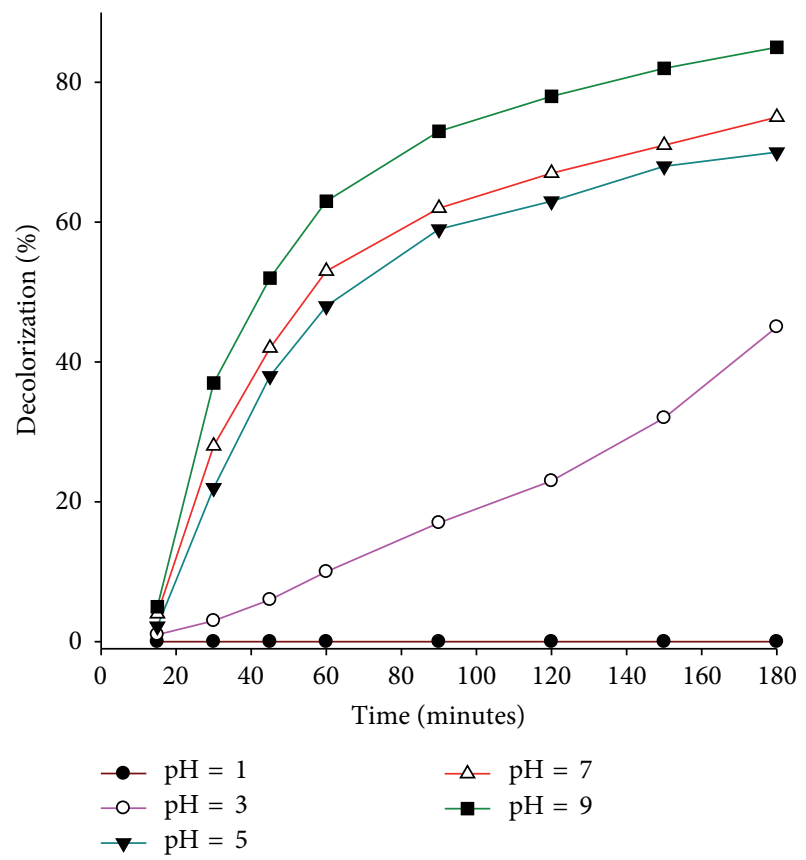

FIGURE 7: Effect of solution $\mathrm{pH}$ on the $\mathrm{MG}$ dye decolorization; $0.6 \mathrm{~g} \mathrm{~L}^{-1}$ of the catalyst; initial dye concentration, $20 \mathrm{ppm} ; 55 \mathrm{~W} \mathrm{Hg}$ lamp; continuous stirring; irradiation time, $180 \mathrm{~min}$; room temperature.

Table 1 shows the dependence of $k$ on $\mathrm{pH}$. As can be seen, the observed degradation is strongly dependent on $\mathrm{pH}$, occurring efficiently at $\mathrm{pH} 9$. However, we have carried out all the experiments in natural $\mathrm{pH}$ (5.3) conditions.

At the end of the studies on $\mathrm{pH}$ effect, the leached nickel cations were followed by atomic spectroscopy. The results showed that the leached nickel cations increase with decreasing $\mathrm{pH}$, so its extent was significantly increased from $\mathrm{pH} 3$ to 1 . But, the leached nickel was not sufficient to determine its value quantitatively and it was only followed qualitatively. This indicates that the Ni-DMG is very stable in the zeolite bed and the leached nickel does not contaminate the solution.

3.2.3. Effect of Temperature. Since the photonic activation occurs at considerably high speeds, it is expected that the photocatalytic system is not sensible to the temperature, and the true activation energy most be then equal to zero. Although considering that the reactions under study occur preferentially in the liquid/solid interface, a nonzero value must be expected as apparent activation energy. It was observed that with increase in the temperature from 25 to $60^{\circ} \mathrm{C}$ (at a $20 \mathrm{ppm} \mathrm{MG}$ concentration containing $0.6 \mathrm{~g} \mathrm{~L}^{-1}$ catalyst), the percentage of decolorization increases (Figure 8 ). With increasing in temperature, the exothermic adsorption of the reactants becomes disfavored due to reducing the value of the apparent activation energy [38]. On the other hand, an increase in temperature decreases the solubility of oxygen in water which is not desirable. Higher temperatures will cause significant evaporation of the solution during 


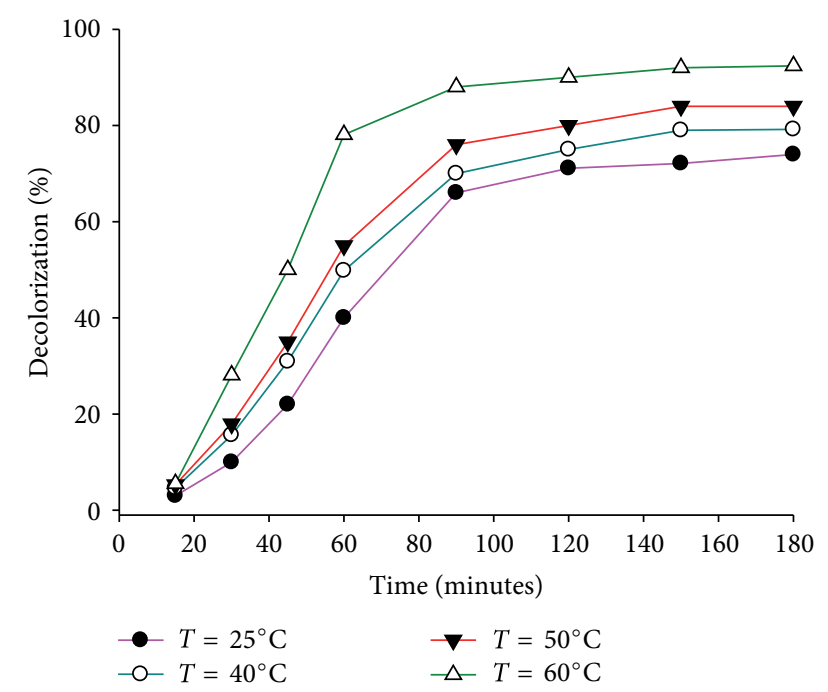

FIGURE 8: Effect of the reaction temperature on decolorization efficiency; $0.6 \mathrm{~g} \mathrm{~L}^{-1}$ of catalyst; initial dye concentration, $20 \mathrm{ppm}$; initial solution $\mathrm{pH} ; 55 \mathrm{~W} \mathrm{Hg}$ lamp; continuous stirring; irradiation time, $180 \mathrm{~min}$; room temperature.

the experiments. Thus, temperature higher than $80^{\circ} \mathrm{C}$ is not recommended. The rate constant values $\left(k, \mathrm{~min}^{-1}\right)$ as a function of temperature on the dye decolorization are presented in Table 1.

3.2.4. Effect of Methyl Green Concentration. The degradation efficiency also depends on the initial concentration of the substrate [3]. The MG decolorization was studied over the concentration covering the range from 10 to $100 \mathrm{ppm}$ by maintaining the other parameters constant. The decolorization is the highest at $40 \mathrm{ppm}$ and thereafter decreases (Figure 9). The life time of hydroxyl radicals is very short (only a few nanoseconds) and thus they can only react where they are formed. Increasing the quantity of MG molecules per volume unit logically enhances the probability of collision between organic matter and oxidizing species, leading to an increase in the decolorization efficiency. It is seen that the decolorization efficiency of dye was decreased with increasing the initial concentration to more than $40 \mathrm{ppm}$. The decrease of the degradation percent with increasing of dye concentration can be due to two reasons. With increasing the amounts of dye, the more of dye molecules will be adsorbed on the surface of the photocatalyst particles and the active sites of the catalyst will be reduced. Therefore, with increasing occupied space of catalyst surface, the generation of hydroxyl radicals will be decreased. Also, increasing the concentration of dye can lead to decreasing the number of photons that is arrived to the surface of catalyst particles. More light is absorbed by molecules of dye and the excitation of photocatalyst particles by photons will be reduced. These results are in good accordance with the literature $[34,37,39,40]$. This is also simplified in Table 1 where the degradation rate constant $(k$, $\min ^{-1}$ ) is listed as a function of initial concentration of the

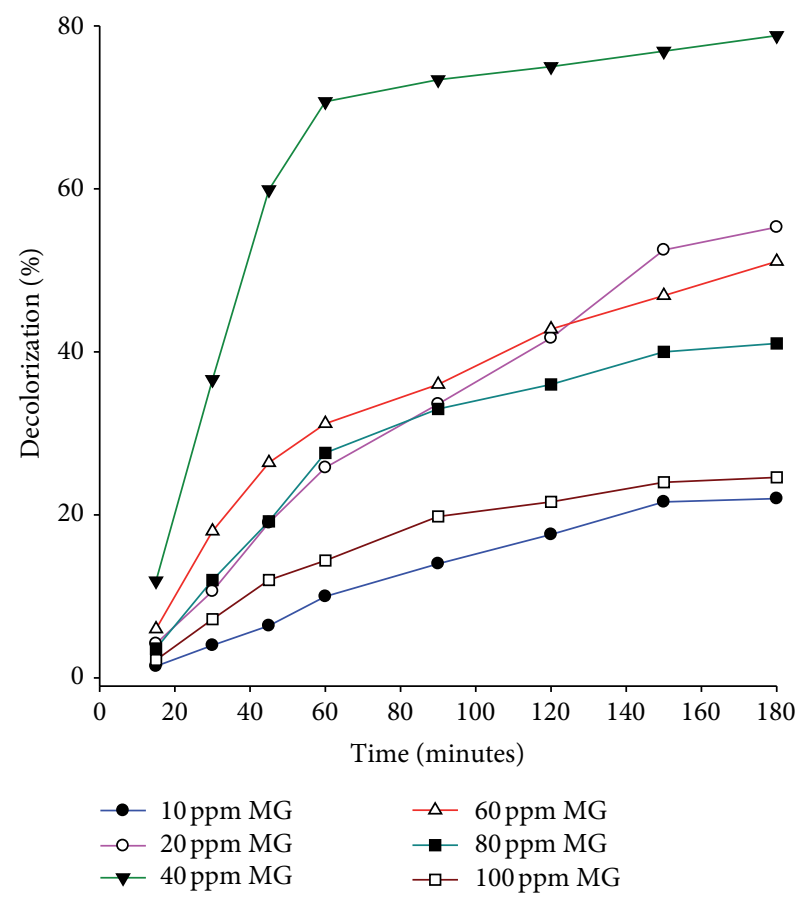

FIGURE 9: Effect of the initial dye concentration on decolorization efficiency of MG; $0.6 \mathrm{~g} \mathrm{~L}^{-1}$ of catalyst; initial solution $\mathrm{pH}, 5.3$; $55 \mathrm{~W}$ Hg lamp; continuous stirring; irradiation time, $180 \mathrm{~min}$; room temperature.

dye. It is apparent that the rate of degradation is a quantitative of concentration dependent and the activity was increased with increasing concentration to $40 \mathrm{ppm}$.

3.2.5. Comparison of MG Degradation over Ni-DMG/ZSM5 and Ni-DMG. The amount of Ni loaded in zeolite was measured by atomic absorption spectroscopy and to be $0.0343 \mathrm{mmol}$ per gram of Ni-DMG/ZSM-5. To determine whether the degradation of MG by Ni-DMG takes place or not, the catalytic activity of $0.02 \mathrm{~g} \mathrm{~L}^{-1} \mathrm{Ni}-\mathrm{DMG}$ was measured under the same above-mentioned experimental conditions. No remarkable activity was noticed due to the presence of $\mathrm{Ni}-\mathrm{DMG}$ as shown in Table 2. It can be concluded that the degradation process occurs insignificantly in the presence of Ni-DMG. The role of the zeolite might be correlated with the adsorption process, in the sense of high surface area and the decrease of particle size [36]. This, in turn, causes an increase in the photodegradation efficiency. Another reason can be related to hydrophobicity properties of the support that is the major factor for the high degradation. The high hydrophobicity of ZSM-5 can be assigned to the influence of the hydrophobic character of structure directing agent for the synthesis of ZSM-5 (e.g., tetrapropylammonium cations) [41]. Hydrophobicity of ZSM-5 increases the adsorption of hydrophobic MG. Highly siliceous ZSM-5 zeolites with low $\mathrm{Al}_{2} \mathrm{O}_{3}$ content are known to have highly hydrophobic surfaces [23]. This observation clearly establishes the importance of support on the activity of degradation of MG. 
TABLE 2: Comparison of the photocatalytic activity of supported and unsupported catalysts.

\begin{tabular}{lcc}
\hline \multirow{2}{*}{ Time (min) } & \multicolumn{2}{c}{ Degradation (\%) } \\
\hline 30 & Ni-DMG/ZSM-5 & Ni-DMG \\
60 & 14.2 & 8 \\
90 & 38 & 18.6 \\
120 & 64 & 19.1 \\
\hline
\end{tabular}

TABLE 3: Reusability of Ni-DMG/ZSM-5 catalyst in the decolorization of MG.

\begin{tabular}{lcc}
\hline \multirow{2}{*}{ Number of cycle } & \multicolumn{2}{c}{ Degradation (\%) } \\
& Calcination in $90^{\circ} \mathrm{C}$ & Calcination in $230^{\circ} \mathrm{C}$ \\
\hline 1 & 80.5 & 88.0 \\
2 & 74.0 & 82.1 \\
3 & 65.3 & 74.3 \\
\hline
\end{tabular}

3.2.6. Catalyst Life. The catalyst stability is a factor that needs to be addressed. After several times of use, the catalyst may be partially desorbed into the solution or decomposed into some fragments. Secondly, the catalyst ability may be deactivated by the reaction intermediates or products formed during the dye degradation [42]. Hence, the reusability of $\mathrm{Ni}-\mathrm{DMG} / \mathrm{ZSM}-5$ catalyst in the degradation of MG was evaluated. The recycling experiments were performed with MG (40 ppm) and Ni-DMG/ZSM-5 $\left(0.6 \mathrm{~g} \mathrm{~L}^{-1}\right)$. After irradiation $(1 \mathrm{~h})$, Ni-DMG/ZSM-5 was recovered by filtration, calcined at $90^{\circ} \mathrm{C}$, and tested again for its activity under identical experimental conditions. Ni-DMG/ZSM-5 exhibited almost the same catalytic activity for three cycles of operation. The experiments were repeated under the same conditions, but the temperature of calcination was $230^{\circ} \mathrm{C}$. Table 3 summarizes the results of experiments. In all cases, the percentage of decolorization was decreased. Two factors are responsible for such a decrease. First, the catalyst concentration was gradually decreased, due to sample analysis [42]. Second, the Ni-DMG/ZSM-5 catalyst experienced a slow bleaching during the reaction process, as observed above in a homogeneous solution. As can be seen, the percentage of decolorization increases upon enhancing the calcinations temperature from 90 to $230^{\circ} \mathrm{C}$. The Ni-DMG/ZSM- 5 calcined at $230^{\circ} \mathrm{C}$ possesses comparatively higher specific surface area than the sample calcined at $90^{\circ} \mathrm{C}$.

The decrease in the activity of the used catalyst must reflect the presence of some adventitious degradation products adsorbed in the zeolite, causing the partial blockage of the pore system or covering the zeolite surface. Preliminary thermal reactivation trials at $230^{\circ} \mathrm{C}$ did lead to an appreciable degradation of Ni-DMG/ZSM-5 photocatalyst as evidenced visually by the color change. Our results show a good agreement with the literature [34].

3.2.7. Comparing the Work with Other Works in MG Degradation. In previous work [39], MG was decolorized by Fe(II)-ophenanthroline/zeolite Y nanocluster. Comparing the results shows that in this work a smaller weight of the NiDMGZSM-5 $\left(0.6 \mathrm{~g} \mathrm{~L}^{-1}\right)$ has been used (with respect to $1.0 \mathrm{~g} \mathrm{~L}^{-1}$ of $\mathrm{Fe}$ (II)-o-phenanthroline/zeolite $\mathrm{Y}$ nanocluster). This can be related to higher hydrophobicity of ZSM-5 with respect to zeolite $\mathrm{Y}$ to adsorb more MG molecules. Biodegradation of some triphenylmethane dyes has been studied [43], and this method has disadvantages with respect to heterogeneous photocatalysis as mentioned in Section 1. Photodegradation of methyl green were studied and the reaction pathway and identification of intermediates was studied by an HPLC [4].

\section{Conclusions}

The MG dye can be more efficiently degraded by Ni-DMG incorporated zeolite ZSM-5 in the presence of UV light. It is important to choose the optimum degradation parameters for increasing the degradation rate. The catalyst can be reused for dye degradation with slightly less efficiency. Zeolite bed shows an important role in the degradation process so that Ni-DMG out of zeolite framework did not show any considerable degradation efficiency.

\section{References}

[1] E. DeOliveira, C. R. Neri, A. O. Ribeiro et al., "Hexagonal mesoporous silica modified with copper phthalocyanine as a photocatalyst for pesticide 2,4-dichlorophenoxiacetic acid degradation," Journal of Colloid and Interface Science, vol. 323, no. 1, pp. 98-104, 2008.

[2] M. H. Habibi and E. Askari, "Photocatalytic degradation of an azo textile dye with manganese-doped $\mathrm{ZnO}$ nanoparticles coated on glass," Iranian Journal of Catalysis, vol. 1, pp. 41-44, 2011.

[3] L. Gomathi Devi, S. Girish Kumar, K. Mohan Reddy, and C. Munikrishnappa, "Photo degradation of methyl orange an azo dye by advanced Fenton process using zero valent metallic iron: influence of various reaction parameters and its degradation mechanism," Journal of Hazardous Materials, vol. 164, no. 2-3, pp. 459-467, 2009.

[4] F. D. Mai, C. C. Chen, J. L. Chen, and S. C. Liu, "Photodegradation of methyl green using visible irradiation in $\mathrm{ZnO}$ suspensions. Determination of the reaction pathway and identification of intermediates by a high-performance liquid chromatography-photodiode array-electrospray ionizationmass spectrometry method," Journal of Chromatography A, vol. 1189, no. 1-2, pp. 355-365, 2008.

[5] V. K. Gupta and Suhas, "Application of low-cost adsorbents for dye removal-a review," Journal of Environmental Management, vol. 90, no. 8, pp. 2313-2342, 2009.

[6] M. H. Pérez, G. Peñuela, M. I. Maldonado et al., "Degradation of pesticides in water using solar advanced oxidation processes," Applied Catalysis B, vol. 64, no. 3-4, pp. 272-281, 2006.

[7] S. Parsons, Advanced Oxidation Processes for Water and Wastewater, IWA Publishing, 2004.

[8] A. Nezamzadeh-Ejhieh and M. Khorsandi, "A comparison between the heterogeneous photodecolorization of an azo dye using Ni/P zeolite and NiS/P zeolite catalysts," , Iranian Journal of Catalysis, vol. 1, no. 2, pp. 99-104, 2011. 
[9] J. G. Lin and Y. S. Ma, "Oxidation of 2-chlorophenol in water by ultrasound/fenton method," Journal of Environmental Engineering, vol. 126, no. 2, pp. 130-137, 2000.

[10] M. Tezuka and M. Iwasaki, "Plasma induced degradation of chlorophenols in an aqueous solution," Thin Solid Films, vol. 316, no. 1-2, pp. 123-127, 1998.

[11] D. M. Willberg, P. S. Lang, R. H. Höchemer, A. Kratel, and M. R. Hoffmann, "Degradation of 4-chlorophenol, 3,4dichloroaniline, and 2,4,6-trinitrotoluene in an electrohydraulic discharge reactor," Environmental Science and Technology, vol. 30, no. 8, pp. 2526-2534, 1996.

[12] M. Pera-Titus, V. García-Molina, M. A. Baños, J. Giménez, and S. Esplugas, "Degradation of chlorophenols by means of advanced oxidation processes: a general review," Applied Catalysis B, vol. 47, no. 4, pp. 219-256, 2004.

[13] J. M. Joseph, R. Varghese, and C. T. Aravindakumar, "Photoproduction of hydroxyl radicals from $\mathrm{Fe}(\mathrm{III})$-hydroxy complex: a quantitative assessment," Journal of Photochemistry and Photobiology A, vol. 146, no. 1-2, pp. 67-73, 2001.

[14] C. Sahoo, A. K. Gupta, and A. Pal, "Photocatalytic degradation of methyl red dye in aqueous solutions under UV irradiation using $\mathrm{Ag}^{+}$doped $\mathrm{TiO}_{2}$," Desalination, vol. 181, no. 1-3, pp. 91-100, 2005.

[15] P. Cieśla, P. Kocot, P. Mytych, and Z. Stasicka, "Homogeneous photocatalysis by transition metal complexes in the environment," Journal of Molecular Catalysis A, vol. 224, no. 1-2, pp. 17-33, 2004.

[16] H. Faghihian and A. Bahranifard, "Application of $\mathrm{TiO}_{2}$-zeolite as photocatalyst for photodegradation of some organic pollutants," Iranian Journal of Catalysis, vol. 1, pp. 45-50, 2011.

[17] M. Huang, C. Xu, Z. Wu, Y. Huang, J. Lin, and J. Wu, "Photocatalytic discolorization of methyl orange solution by $\mathrm{Pt}$ modified $\mathrm{TiO}_{2}$ loaded on natural zeolite," Dyes and Pigments, vol. 77, no. 2, pp. 327-334, 2008.

[18] G. Murali Dhar, B. N. Srinivas, M. S. Rana, M. Kumar, and S. K. Maity, "Mixed oxide supported hydrodesulfurization catalysts-a review," Catalysis Today, vol. 86 , no. $1-4$, pp. $45-60$, 2003.

[19] S. Anandan, A. Vinu, N. Venkatachalam, B. Arabindoo, and V. Murugesan, "Photocatalytic activity of $\mathrm{ZnO}$ impregnated $\mathrm{H} \beta$ and mechanical mix of $\mathrm{ZnO} / \mathrm{H} \beta$ in the degradation of monocrotophos in aqueous solution," Journal of Molecular Catalysis A, vol. 256, no. 1-2, pp. 312-320, 2006.

[20] G. Yan, X. Wang, X. Fu, and D. Li, "A primary study on the photocatalytic properties of HZSM-5 zeolite," Catalysis Today, vol. 93-95, pp. 851-856, 2004.

[21] A. Nezamzadeh-Ejhieh and Kh. Shirvani, "CdS loaded an Iranian clinoptilolite as a heterogeneous catalyst in photodegradation of p-aminophenol," Journal of Chemistry, vol. 2013, Article ID 541736, 11 pages, 2013.

[22] I. Othman, R. M. Mohamed, I. A. Ibrahim, and M. M. Mohamed, "Synthesis and modification of ZSM-5 with manganese and lanthanum and their effects on decolorization of indigo carmine dye," Applied Catalysis A, vol. 299, no. 1-2, pp. 95-102, 2006.

[23] M. Takeuchi, T. Kimura, M. Hidaka, D. Rakhmawaty, and M. Anpo, "Photocatalytic oxidation of acetaldehyde with oxygen on $\mathrm{TiO}_{2}$ /ZSM-5 photocatalysts: effect of hydrophobicity of zeolites," Journal of Catalysis, vol. 246, no. 2, pp. 235-240, 2007.

[24] M. Ghiaci, F. Seyedeyn-Azad, and R. Kia, "Fast and efficient synthesis of ZSM-5 in a broad range of $\mathrm{SiO}_{2} / \mathrm{Al}_{2} \mathrm{O}_{3}$ without using seeding gel," Materials Research Bulletin, vol. 39, no. 9, pp. 1257-1264, 2004.

[25] R. Q. Long and R. T. Yang, "Superior ion-exchanged ZSM5 catalysts for selective catalytic oxidation of ammonia to nitrogen," Chemical Communications, no. 17, pp. 1651-1652, 2000.

[26] P. Wang, B. Shen, D. Shen, T. Peng, and J. Gao, "Synthesis of ZSM-5 zeolite from expanded perlite/kaolin and its catalytic performance for FCC naphtha aromatization," Catalysis Communications, vol. 8, no. 10, pp. 1452-1456, 2007.

[27] K. B. Sidhpuria, P. A. Parikh, P. Bahadur, and R. V. Jasra, "Simplified synthesis of isomorphously nickel substituted ZSM5," Journal of Porous Materials, vol. 15, no. 4, pp. 481-489, 2008.

[28] A. Nezamzadeh-Ejhieh and Z. Salimi, "Heterogeneous photodegradation catalysis of o-phenylenediamine using $\mathrm{CuO} / \mathrm{X}$ zeolite," Applied Catalysis A, vol. 390, no. 1-2, pp. 110-118, 2010.

[29] E. M. Flanigen, H. Khatami, H. A. Szymanski, E. M. Flanigen, and L. B. Sand, "Infrared structural studies of zeolite frameworks," in Advances in Chemistry Series, p. 201, American Chemical Society, Washington, DC, USA, 1971.

[30] H. Feng, C. Li, and H. Shan, "In-situ synthesis and catalytic activity of ZSM-5 zeolite," Applied Clay Science, vol. 42, no. 3-4, pp. 439-445, 2009.

[31] A. Nezamzadeh-Ejhieh and M. Khorsandi, "Heterogeneous photodecolorization of eriochrome black $\mathrm{T}$ using $\mathrm{Ni} / \mathrm{P}$ zeolite catalyst," Desalination, vol. 262, no. 1-3, pp. 79-85, 2010.

[32] A. Dyer, An Introduction to Zeolite Molecular Sieve, John Wiley \& Sons, Chichester, UK, 1988.

[33] M. J. A. Sales, S. C. L. Dias, J. A. Dias, and T. D. A. P. F. Pimentel, "Stability studies of ZSM-5/polystyrene and Y/ polystyrene composites," Polymer Degradation and Stability, vol. 87, no. 1, pp. 153-160, 2005.

[34] A. Nezamzadeh-Ejhieh and M. Amiri, "CuO supported clinoptilolite towards solar photocatalytic degradation of p-aminophenol," Powder Technology, vol. 235, pp. 279-288, 2013.

[35] A. Nezamzadeh-Ejhieh and Z. Banan, "Kinetic investigation of photocatalytic degradation of dimethyldisulfide by zeolite acontaining nano CdS," Iranian Journal of Catalysis, vol. 2, no. 2, pp. 77-81, 2012.

[36] Z. M. El-Bahy, M. M. Mohamed, F. I. Zidan, and M. S. Thabet, "Photo-degradation of acid green dye over Co-ZSM-5 catalysts prepared by incipient wetness impregnation technique," Journal of Hazardous Materials, vol. 153, no. 1-2, pp. 364-371, 2008.

[37] A. Nezamzadeh-Ejhieh and M. Khorsandi, "Photodecolorization of Eriochrome Black T using NiS-P zeolite as a heterogeneous catalyst," Journal of Hazardous Materials, vol. 176, no. 1-3, pp. 629-637, 2010.

[38] A. E. H. Machado, J. A. de Miranda, R. F. de Freitas et al., "Destruction of the organic matter present in effluent from a cellulose and paper industry using photocatalysis," Journal of Photochemistry and Photobiology A, vol. 155, no. 1-3, pp. 231-241, 2003.

[39] A. Nezamzadeh-Ejhieh and E. Shahriari, "Heterogeneous photodecolorization of methyl green catalyzed by $\mathrm{Fe}(\mathrm{II})$-ophenanthroline/zeolite Y nanocluster," International Journal of Photoenergy, vol. 2011, Article ID 518153, 10 pages, 2011.

[40] A. Nezamzadeh-Ejhieh and S. Hushmandrad, "Solar photodecolorization of methylene blue by $\mathrm{CuO} / \mathrm{X}$ zeolite as a heterogeneous catalyst," Applied Catalysis A, vol. 388, no. 1-2, pp. 149-159, 2010. 
[41] A. V. Goretsky, L. W. Beck, S. I. Zones, and M. E. Davis, "Influence of the hydrophobic character of structure-directing agents for the synthesis of pure-silica zeolites," Microporous and Mesoporous Materials, vol. 28, no. 3, pp. 387-393, 1999.

[42] A. Sun, Z. Xiong, and Y. Xu, "Removal of malodorous organic sulfides with molecular oxygen and visible light over metal phthalocyanine," Journal of Hazardous Materials, vol. 152, no. 1, pp. 191-195, 2008.

[43] W. Azmi, R. K. Sani, and U. C. Banerjee, "Biodegradation of triphenylmethane dyes," Enzyme and Microbial Technology, vol. 22, no. 3, pp. 185-191, 1998. 

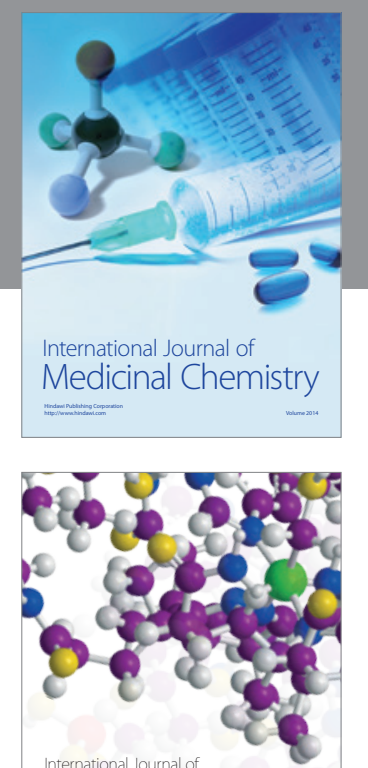

\section{Carbohydrate} Chemistry

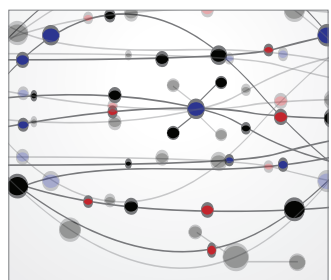

The Scientific World Journal
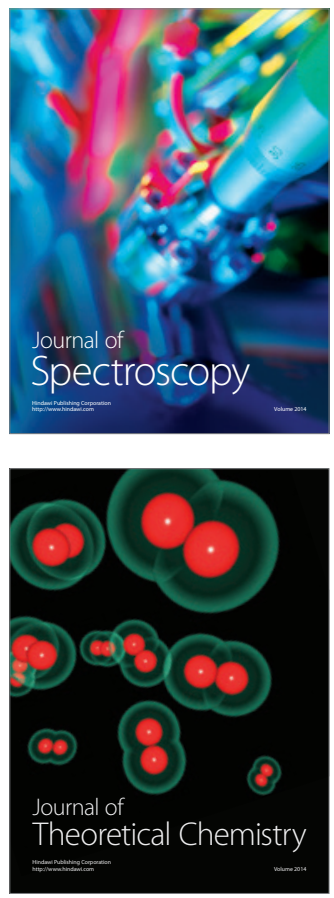
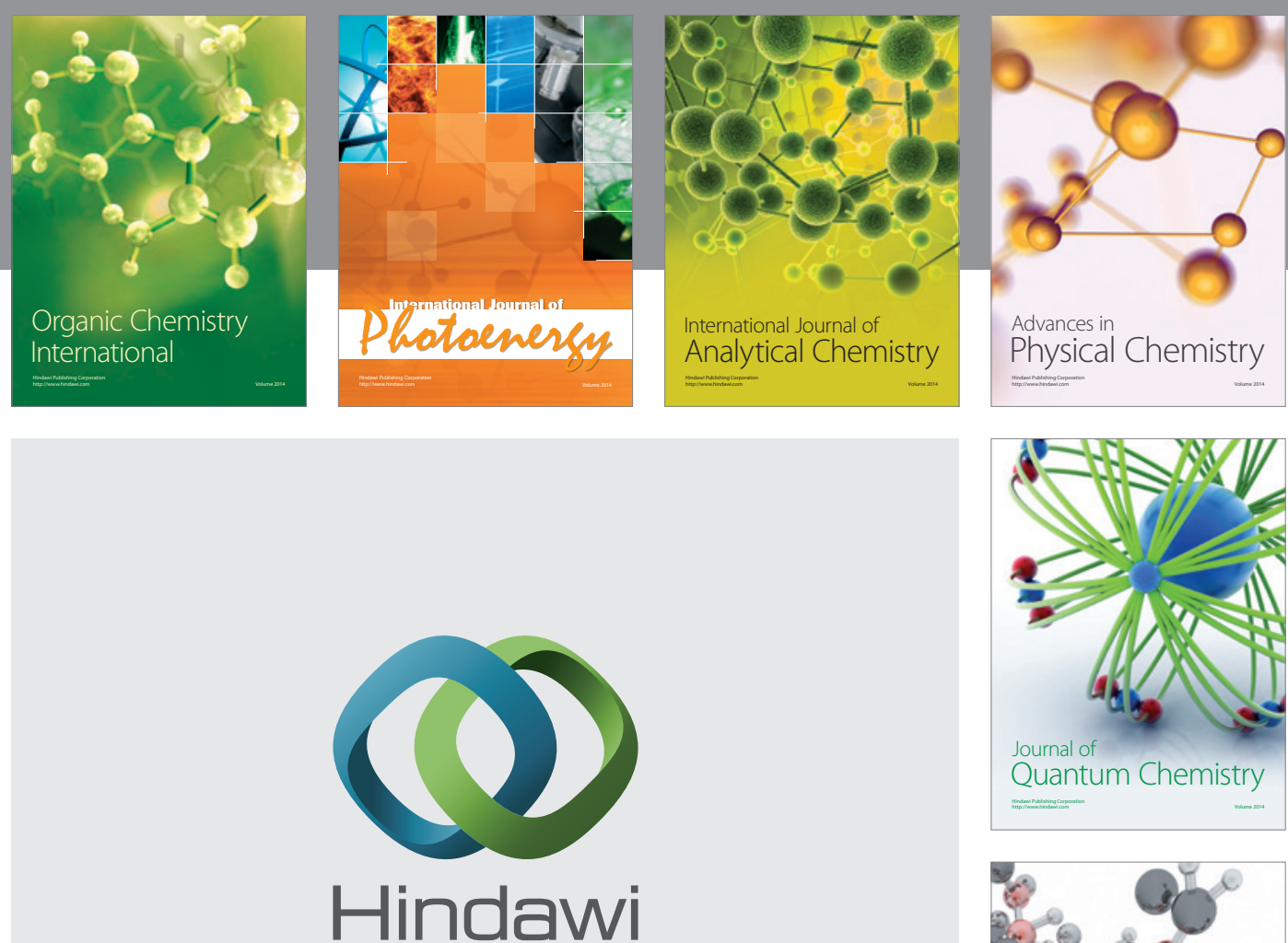

Submit your manuscripts at

http://www.hindawi.com

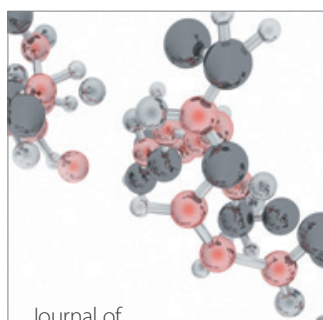

Analytical Methods

in Chemistry

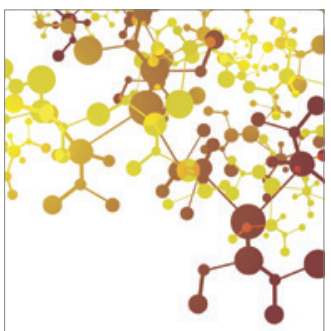

Journal of

Applied Chemistry

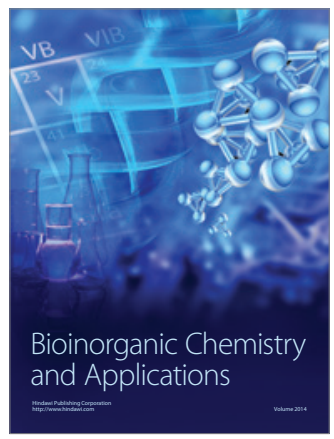

Inorganic Chemistry
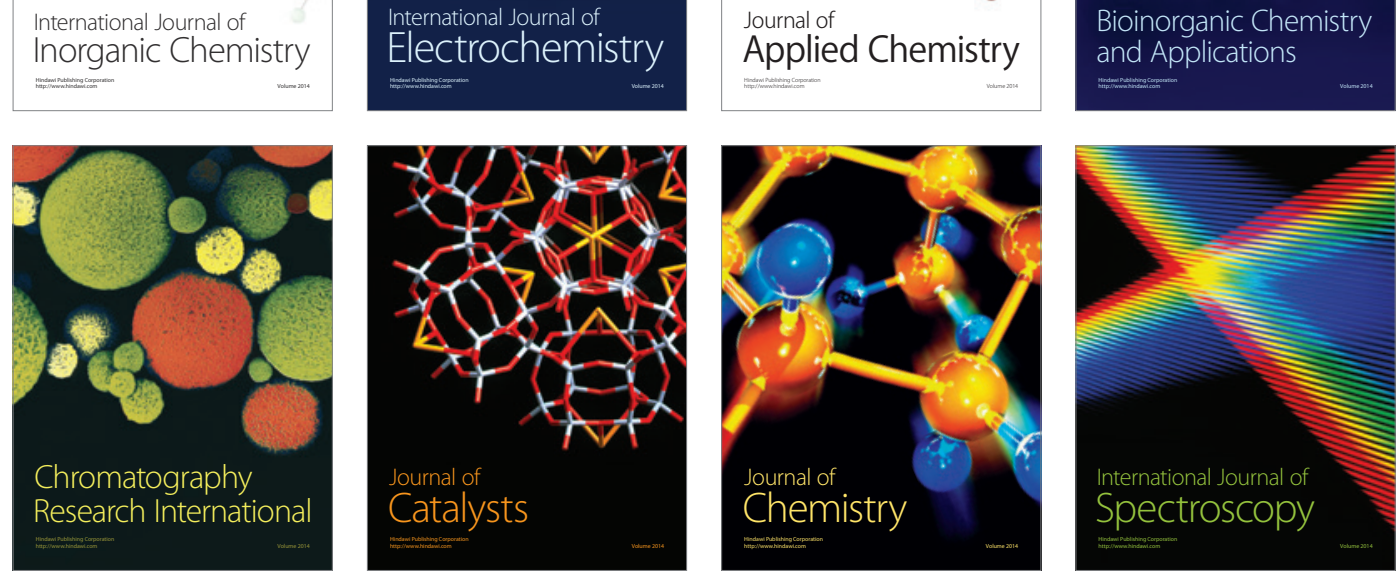